TecnoLógicas

ISSN-p 0123-7799

ISSN-e 2256-5337

Vol. 21, No. 42, pp. 51-62

Mayo-agosto de 2018

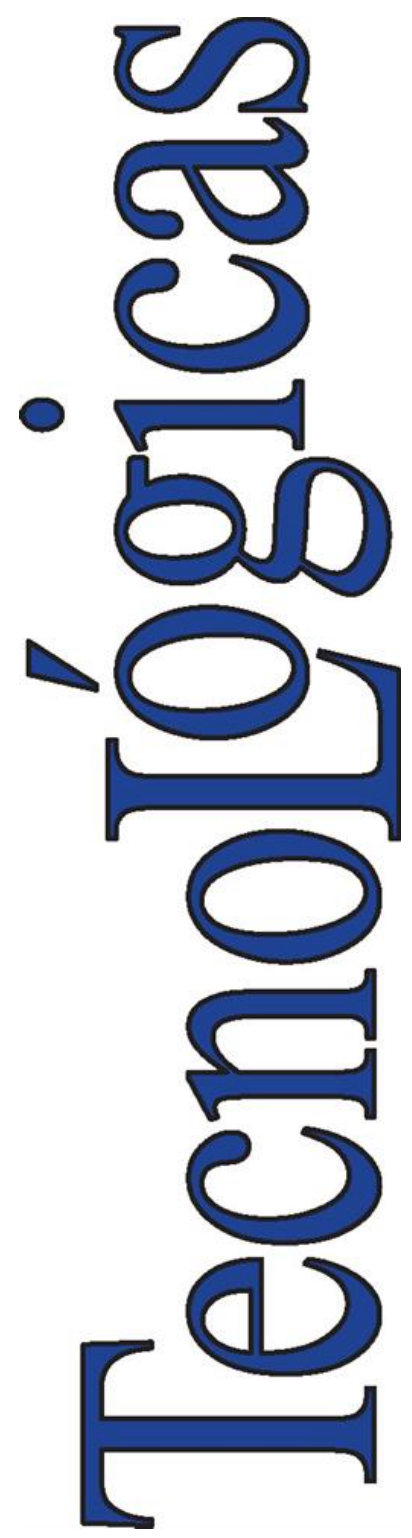

(C) Copyright 2015 por autores y Tecno Lógicas Este trabajo está licenciado bajo una Licencia Internacional Creative Commons Atribución (CC BY)

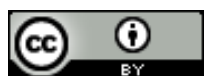

Artículo de Investigación/Research Article

\section{Implementation of an analytical formulation for LEMP to assess the lightning performance of a distribution line}

\section{Implementación de una formulación analítica del LEMP para estimar el desempeño de líneas de distribución frente a rayos}

\author{
Edison Soto ${ }^{1}$, y Ernesto Pérez ${ }^{2}$
}

Recibido: 05 de enero de 2018

Aceptado: 09 de abril de 2018

Cómo citar / How to cite

E. Soto, y E. Pérez, Implementation of an analytical formulation for LEMP to assess the lightning performance of a distribution line. TecnoLógicas, vol. 21, no. 42, pp. 51-62, 2018.
$1 \mathrm{PhD}$ in Engineer, Msc in Electrical Engineer, Escuela de Ingeniería Eléctrica, Electrónica y de Telecomunicaciones, Universidad Industrial de Santander, easotor@uis.edu.co

$2 \mathrm{PhD}$ in Engineer, Msc, in Electrical Engineer, Departamento de Energía Eléctrica y Automática, Universidad Nacional de Colombia, eperezg@unal.edu.co 


\section{Abstract}

This paper presents the implementation of an analytical formulation to calculate the lightning electromagnetic pulse (LEMP) assuming a current wave-shape linearly rising with flat top and a transmission Line (TL) return-stroke model. It also describes the development of the expressions for the image dipoles required to calculate the vertical electric field, the azimuthal magnetic field and, specially, the horizontal electric field. The expressions to calculate the contribution of source dipoles were detailed in a previous publication by other authors. The complete formulation is used to calculate electromagnetic fields and lightninginduced voltages on a typical overhead distribution line. The results were compared with traditional formulas to calculate the LEMP (such as Rubinstein's) and to calculate induced voltages (such as Rusck's) showing errors below 1\%. If a more complex wave shape was used (such as Heidler's), errors below 5\% were found. Additionally, the formula was employed to calculate the flashover rate of a distribution line above a ground with infinite and finite conductivity. Errors less than 5\% were found compared to the results obtained in the IEEE 1410 Standard. On the other hand, the computation time required to the assessment of an overhead line indirect lightning performance is reduced by half when the analytical formula is used.

\section{Keywords}

Lightning, lightning induced voltages, distribution lines, analytical formulas, electromagnetic field, flashover rate.

\section{Resumen}

Este artículo presenta la implementación de una formulación analítica para calcular el campo electromagnético producido por rayo (LEMP), asumiendo una forma de onda de la corriente tipo rampa plana y un modelo de línea de transmisión (TL) para la descarga de retorno. Se presenta el desarrollo de las expresiones para los dipolos imágenes necesarios para calcular el campo eléctrico vertical, el campo magnético azimutal y especialmente el campo eléctrico horizontal. Las expresiones para calcular la contribución de los dipolos fuentes se presentaron en una publicación previa de otros autores. La formulación completa se usó para calcular los campos electromagnéticos y las tensiones inducidas por rayo en una línea de distribución aérea típica. Los resultados fueron comparados con las fórmulas tradicionales para calcular el LEMP como la fórmula de Rubinstein y para calcular tensiones inducidas como la fórmula de Rusck mostrando errores menores al 1\%. Si una forma de onda más compleja se usa como la fórmula de Heidler, se encuentran errores menores al 5\%. Adicionalmente, la fórmula se empleó para calcular la tasa de fallas de una línea de distribución aérea para terrenos con conductividad finita. Se encontraron errores menores al 5\% comparados con las obtenidas en el estándar IEEE 1410. De otro lado, el tiempo de cómputo requerido para la evaluación del desempeño ante rayos de líneas de distribución se reduce a la mitad cuando se usa la fórmula analítica.

\section{Palabras clave}

Rayos, tensiones inducidas por rayos, líneas de distribución, fórmula analítica, campo electromagnético, tasa de fallas. 


\section{INTRODUCTION}

The calculation of lightning induced voltages on distribution lines is of crucial importance because the indirect impacts are a major cause of outages in this kind of lines [1]. This is because the high frequency of indirect strikes compared to direct ones and the reduced insulation level of the distribution lines, which makes them vulnerable to indirect lightning-induced voltages [2]. For the calculation of lightning-induced voltages, a very well-known methodologies adopted, which considered the following steps [3]:

1. To adopt a spatial-temporal distribution of the current along the channel $i\left(z^{\prime}, t\right)$.

2. On the basis of the return stroke current, the electromagnetic field is calculated along the distribution line.

3 . The electromagnetic field along the line is used in the coupling model to calculate the voltage on the line.

From the previous steps, the calculation of the electromagnetic field has the highest computational effort, because Equations (1), (2) and (3) are solved with numerical methods [4][5]. Some methods could be used to decrease the computational time required: Thottappillil et al [6] derived a formula that allows the calculation of electric and magnetic fields for a return stroke with a velocity equal to the speed of light $v=c$. Rubinstein et al [7] developed expressions of the electromagnetic field for a spatial-temporal distribution of the given current for a step function calculated at ground level. Barbosa et al [8] proposed a formula for the calculation of the horizontal electric field considering finitely conducting earth in time domain. Napolitano [9] developed an analytical formula to calculate the electromagnetic field generated by lightning assuming a current wave shape linearly rising with flat top that allows the reduction of the computation time of the lightning-induced voltage calculation, thus avoiding the use of slower numerical methods. Nevertheless, in the analytical solution derived by Napolitano in [9] only the source terms are presented, which are not enough to compute the electromagnetic field. In order to compute lightning-induced voltage on an overhead distribution line adopting the traditional methodologies [3] the vertical electric field $E_{z}$ and the azimuthal magnetic field $H_{\varphi}$ are calculated at ground level, meanwhile the horizontal electric field $E_{\rho}$ is calculated at the height of the line. Each field is obtained by means of the Master and Uman equations [10][11] deduced for perfectly conducting ground. In the case of the vertical electric field $E_{z}$ and the azimuthal magnetic field $H_{\varphi}$ components at ground level, it is just necessary to derive the equations for either the source or the dipole contribution and then obtain the total field multiplying it by two, because of the equal contribution from the source or the image dipoles at ground level. In the case of the horizontal electric field $E_{\rho}$, it must be calculated at height $h$, where the contribution of the source and dipole terms are required.

In this paper, the image terms to calculate the horizontal electric field are derived and implemented in Yaluk Draw software [12] to calculate lightning-induced voltages and the lightning performance of a typical distribution line. The implemented analytical formulation with traditional numerical methodologies is presented.

This paper is organized as follows: Section 2 presents the derived terms of the horizontal electric field corresponding to image dipoles. Section 3 presents the calculation of lightning-induced voltages using the analytical expression for calculating the electromagnetic field. Section 4 presents the lightning performance of a distribution line in comparison with the results found in the standard IEEE $1410-2010$. Finally, the conclusions of the work are presented. 


\section{ELECTROMAGNETIC CALCULATION}

Master and Uman [10] derived analytical expressions for computing the electromagnetic field generated by lightning. These equations in cylindrical coordinates are [11].

Equations have been traditionally solved by means of numerical methods [3] [5]. Napolitano et al [9] solved Equations (1), (2) and (3) assuming a linear-front and flat-top lightning current wave shape and a TL model. The calculation of the electromagnetic field requires the sum of the contribution of the sources and image dipoles.

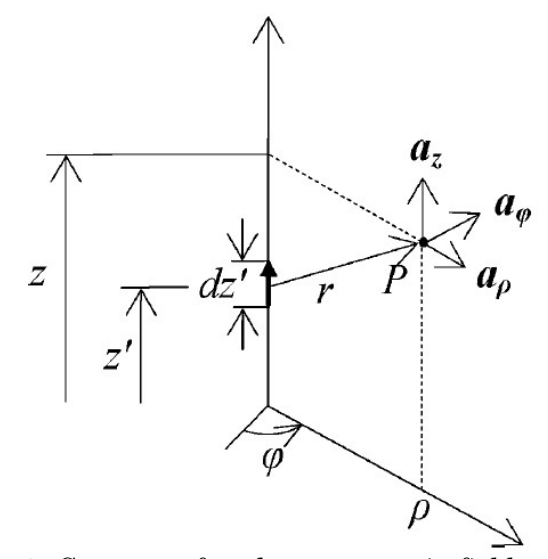

Fig. 1. Geometry for electromagnetic field calculation in cylindrical coordinates. Source: [9]

$$
\begin{gathered}
d E_{\rho}(\rho, z, t)=\frac{\rho\left(z-z^{\prime}\right) d z^{\prime}}{4 \pi \varepsilon}\left[\frac{3}{c r^{4}} i\left(z^{\prime}, t-\frac{r}{c}\right)+\frac{1}{c^{2} r^{3}} \frac{\partial i\left(z^{\prime}, t-\frac{r}{c}\right)}{\partial t}+\frac{3}{r^{5}} \int_{0}^{t} i\left(z^{\prime}, t-\frac{R}{c}\right) d \tau\right] \\
d E_{z}(\rho, z, t)=\frac{d z^{\prime}}{4 \pi \varepsilon}\left[\frac{2\left(z-z^{\prime}\right)^{2}-\rho^{2}}{c r^{4}} i\left(z^{\prime},-r / c\right)-\frac{\rho^{2}}{c^{2} R^{3}} \frac{\partial i\left(z^{\prime}, t-r / c\right)}{\partial t}+\frac{2\left(z-z^{\prime}\right)^{2}-\rho^{2}}{r^{5}} \int_{0}^{t} i\left(z^{\prime}, t-R / c\right) d \tau\right] \\
d H \varphi=\frac{\rho d z^{\prime}}{4 \pi r^{2}}\left[\frac{1}{r} i\left(z^{\prime}, t-r / c\right)+\frac{1}{c} \frac{\partial i\left(z^{\prime}, t-r / c\right)}{\partial t}\right]
\end{gathered}
$$

where $i\left(z^{\prime}, t\right)$ is the current along the return-stroke channel at height $z^{\prime} ; z^{\prime}$, the variable of the height along the channel (see Fig. 1); c, the speed of light in free space; and $r$, the distance between point $\mathrm{P}$ and the infinitesimal current, given by (4).

$$
\mathrm{r}=\sqrt{\rho^{2}+\left(z-z^{\prime}\right)^{2}}
$$

The expressions to calculate the image terms of the horizontal electric field $E_{\rho}$ are presented below:

The wave shape of the lightning current is linear-front and flat-top, according to Equations (5) and (6):

$$
\begin{gathered}
i(0, t)=\frac{I_{p}}{t_{f}} t, t \leq t_{f} \\
i(0, t)=I_{p}, t \geq t_{f}
\end{gathered}
$$

where $I_{p}$ is the peak value of the current and $t_{f}$ is the front time.

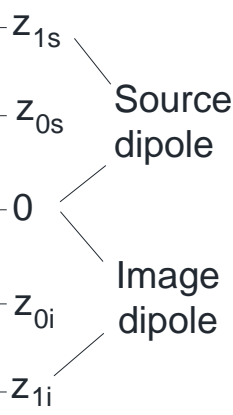

Fig. 2. Integration limits of the dipole image. Source: Authors.

The solutions of (1), (2) and (3) need to be divided into two integration limits: the 
first one from $z_{0 i}$ to $z_{1 i}$, and the second between $z_{1 i}$ and zero, as seen in Fig. 2

$z_{0 i}$ represents the height of the last dipole turned on when the front-wave travels from the ground to height $z_{0 i}$, which is obtained from equation (8) derived from condition (7):

$$
\begin{gathered}
t \geq-\frac{z^{\prime}}{v}+\frac{r}{c} \quad \begin{array}{r}
\text { The expression for the contribution } \\
\text { the image dipoles to the horizontal el } \\
\text { field } E_{\rho} \text { is given by (11), (12) and (13). }
\end{array} \\
z_{0 i}=\frac{\left(-\frac{t}{v}-\frac{z}{c^{2}}\right)-\sqrt{\left(\left(-\frac{t}{v}-\frac{z}{c^{2}}\right)^{2}-\left(\frac{1}{v^{2}}-\frac{1}{c^{2}}\right)\left(t^{2}-\frac{\rho^{2}+z^{2}}{c^{2}}\right)\right)}}{\left(\frac{1}{v^{2}}-\frac{1}{c^{2}}\right)} \\
z_{1 i}=\frac{\left(-\frac{t-t_{f}}{v}-\frac{z}{c^{2}}\right)-\sqrt{\left(\left(-\frac{t-t_{f}}{v}-\frac{z}{c^{2}}\right)^{2}-\left(\frac{1}{v^{2}}-\frac{1}{c^{2}}\right)\left(\left(t-t_{f}\right)^{2}-\frac{\rho^{2}+z^{2}}{c^{2}}\right)\right)}}{\left(\frac{1}{v^{2}}-\frac{1}{c^{2}}\right)} \\
A_{i}(\zeta)=\frac{E_{\rho i}(\rho, z, t)=\frac{I_{p}}{4 \pi \varepsilon}\left[A_{i}\left(z_{0 i}\right)-A_{i}\left(z_{1 i}\right)+B_{i}\left(z_{1 i}\right)-B_{i}(0)\right]}{2 t_{f} \sqrt{\left[\rho^{2}+(z-\zeta)^{2}\right]^{3}}\left\{\frac{2}{v \rho}\left(t+\frac{z}{v}\right)(z-\zeta)^{3}+\rho\left(\frac{3}{v^{2}}-\frac{1}{c^{2}}\right)(z-\zeta)^{2}+\rho\left(t+\frac{z}{v}\right)^{2}+\rho^{3}\left(\frac{2}{v^{2}}-\frac{1}{c^{2}}\right)\right\}} \\
B_{i}(\zeta)=\frac{\rho\left(t-\frac{t_{f}}{2}+\frac{z}{v}\right)+\frac{1}{v \rho}(z-\zeta)^{3}}{\sqrt{\left[\rho^{2}+(z-\zeta)^{2}\right]^{3}}}
\end{gathered}
$$

On the other hand, $z_{1 i}$ is the height which below that point the current has a constant value $I_{p} . z_{1 i}$ is obtained from condition (9) and calculated from (10).

$$
\mathrm{t} \geq t_{f}-\frac{z^{\prime}}{v}+\frac{r}{c}
$$

The expression for the contribution of the image dipoles to the horizontal electric
The expression for the contribution of the source dipoles $E_{\rho s}$ to the horizontal electric field was presented in [9] in terms of $z_{0 s}$ and $z_{1 s}$, as in Fig. 2 The total horizontal field $E_{\rho}$ is the sum of the image and source terms (14)

$$
E_{\rho}=E_{\rho i}+E_{\rho s}
$$

In order to calculate the vertical electric field $E_{z}$ and the azimuthal magnetic field $H_{\varphi}$ at ground level, it is possible to use the equations developed by Napolitano [9] derived only for the source terms and mul- tiplied by (2). This is explained by the fact that fields $E_{z}$ and $H_{\varphi}$ calculated at ground level receive equal contribution from the source and image dipoles; therefore, only one of them needs to be calculated.

\section{CALCULATION OF LIGHTNING- INDUCED VOLTAGES USING ANALYTICAL EQUATIONS}

In order to test the validity of the equations presented in the previous section, a 
comparison with some approximations in the literature is presented.

\subsection{Comparison with other analytical equations}

Initially, the electric fields calculated by means of the analytical equations presented in the last section are compared with the equations developed by Rubinstein [6] to calculate electromagnetic fields considering a step current waveform at ground level. For comparison purposes, the linear-front and flat-top lightning current wave-shape is assumed to have a front time $t_{f}=0 \mu \mathrm{s}$, which is similar to the step current waveform by Rubinstein [13]. The vertical electric field at ground level obtained at a distance of $100 \mathrm{~m}$ from a lightning channel with a peak current of $30 \mathrm{kA}$ is presented in Fig. 3. Good agreement between the two methodologies, with mean errors lower than $1 \%$, can be observed.

Afterwards, the analytical equations presented in Section 2 were implemented in Yaluk Draw software [12], which uses the Agrawal coupling model [14] to compute lightning-induced transients on overhead lines. In order to evaluate the implementation, the simulation included a $2 \mathrm{~km}$ overhead line with a height of $10 \mathrm{~m}$, a con- ductor radius of $5 \mathrm{~mm}$ and matched at both ends to avoid reflections. The lightning strike was placed $100 \mathrm{~m}$ from the center of the line, as shown in Fig. 4. In turn, Fig. 5 reports the results of the lightning-induced voltage at one of the line extremities considering the analytical formulation and numerically solving equations (1), (2) and (3). The maximum value of the induced voltage using the analytical formulation is the same as the one obtained by means of Rusck's Formula [15]

\subsection{Comparison with numerical solu- tions}

The following is a comparison between the lightning electric fields and induced voltages calculated by means of the analytical equations presented in Section 2 and the numerical solution of equations (1), (2) and (3). In this case, the effect of the lightning front time is taken into account, assuming a linear-front and flat-top (LFFT) lightning current wave-shape with a front time $t_{f}=3 \mu \mathrm{s}$. The lightning current assumed in the case of the numerical solution is a Heidler function, which was adjusted to find the best fit with the linear-

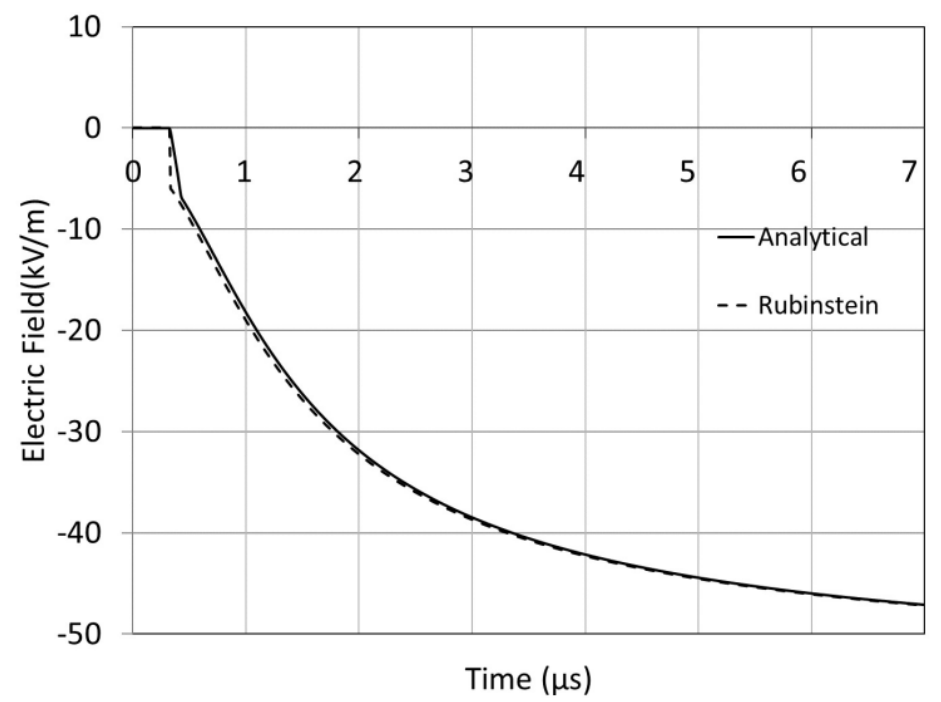

Fig. 3. Vertical Electric Field obtained at a distance of $100 \mathrm{~m}$ from a lightning channel using Analytical formulas and Rubinstein's equations. Source: Authors. 


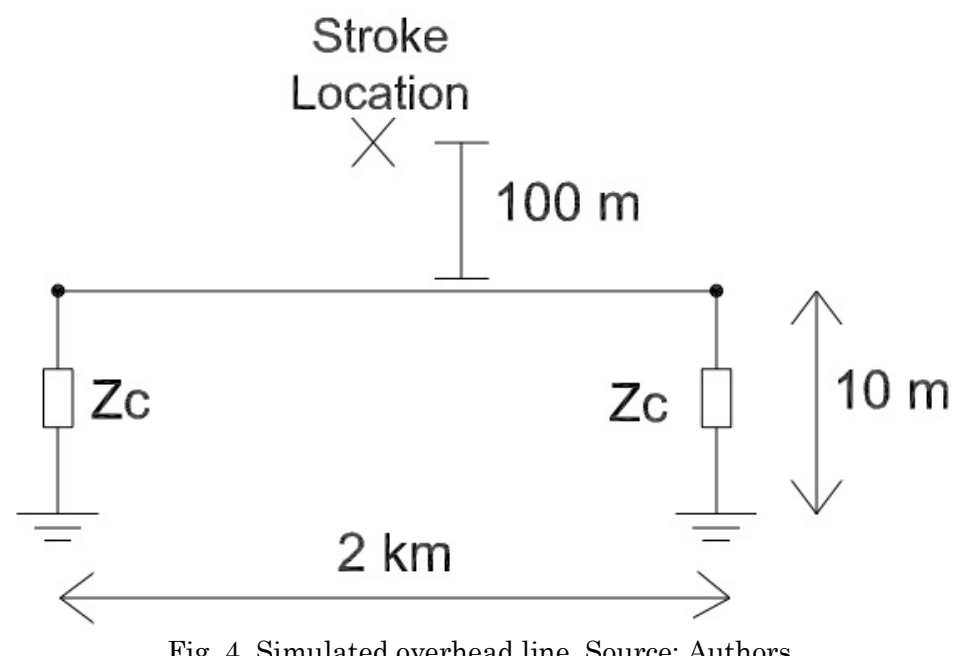

Fig. 4. Simulated overhead line. Source: Authors.

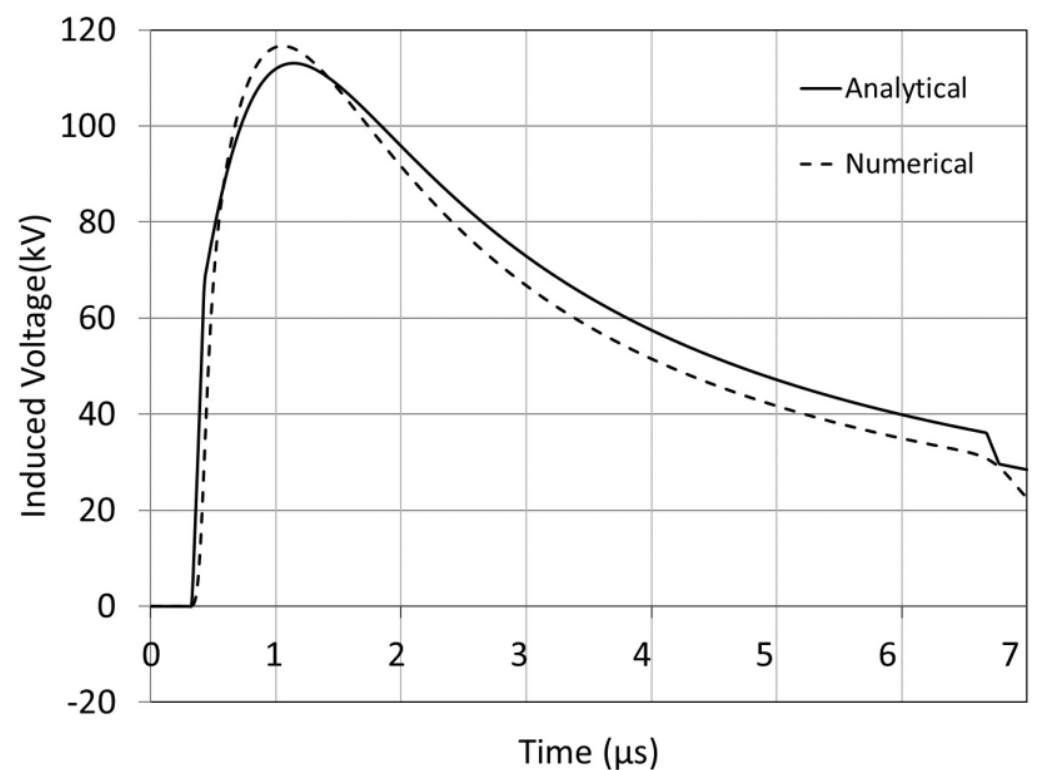

Fig. 5. Lightning-induced voltage obtained by Analytical Formula and Master and Uman's Equations assuming $t_{f}=0 \mu s$. Source: Authors.

front and flat-top (LFFT). The two waveforms are shown in Fig. 6. The resulting parameters of the Heidler function were:

$$
I_{01}=28 k A, \tau_{11}=1.3 \mu s, \tau_{12}=1 \mu s, n=4
$$

The vertical and horizontal electric fields obtained at a distance of $100 \mathrm{~m}$ from a lightning channel with the two previous waveforms at its base are shown in Fig. 7 and Fig. Fig. 8, respectively. A good agreement between analytical and numerical calculations can be observed. The varia- tions are explained by the little differences in simulated currents in both cases.

Fig. 9 shows the calculated lightninginduced voltage at one extremity of the line for the location of the stroke shown in Fig. 4, assuming the two previous lightning current base. The peak value of induced voltages has an error lower than 5\%, which may be explained by the fact that the wave shape of currents differs mainly on the front, which is associated with the higher contribution to the induction. 
Implementation of an analytical formulation for LEMP to assess the lightning performance of a distribution line

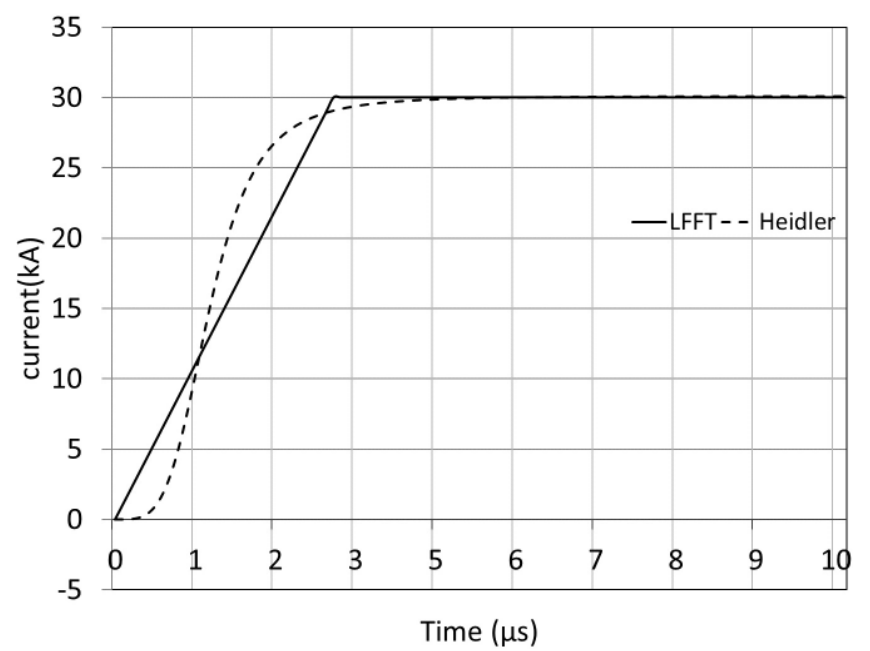

Fig. 6. Simulated currents. LFFT (Linear-front and flat top) and Heidler function. Source: Authors.

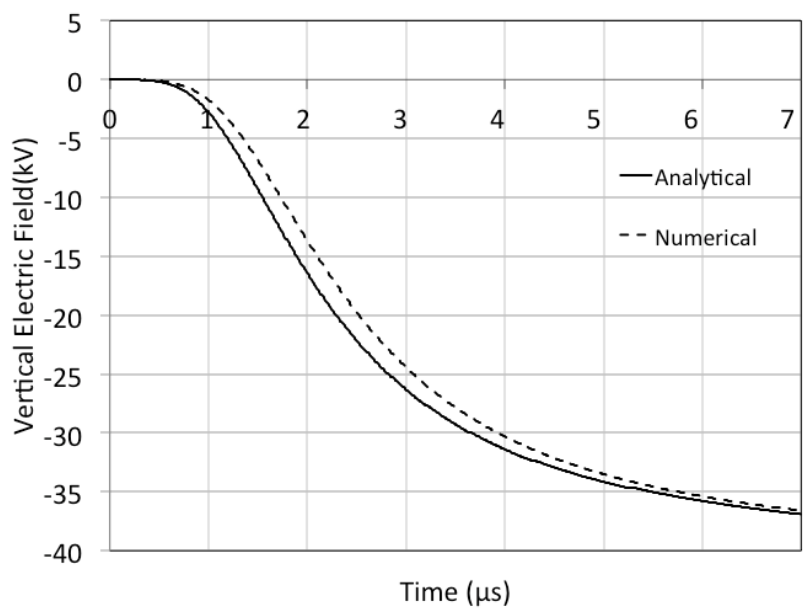

Fig. 7. Vertical Electric Field at a distance of $100 \mathrm{~m}$ from a lightning current with $t_{f}=3 \mu \mathrm{s}$, calculated by the analytical formula and Master and Uman's equations. Source: Authors.

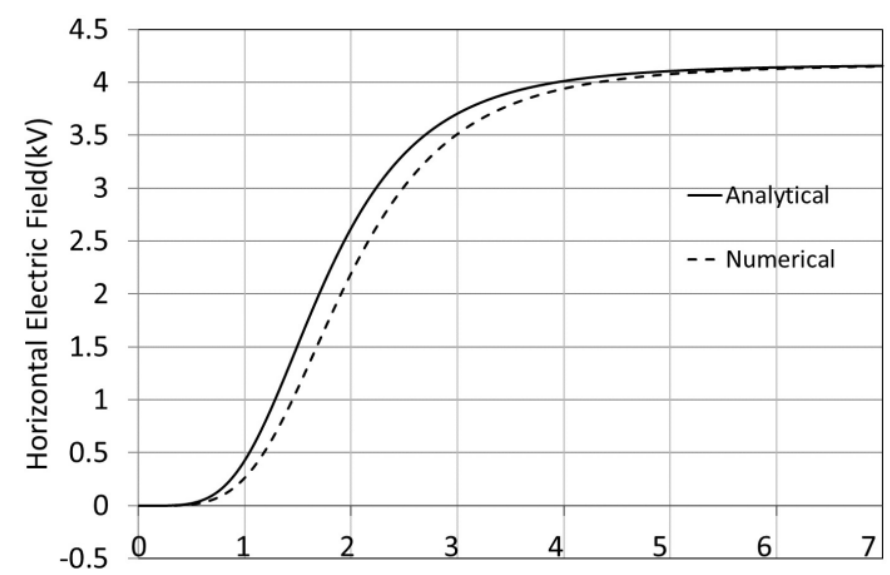

Time ( $\mu s)$

Fig. 8. Horizontal Electric Field at a distance of $100 \mathrm{~m}$ from a lightning current with $\mathrm{tf}=3 \mu \mathrm{s}$, calculated by the analytical formula and Master and Uman's equations. Source: Authors. 


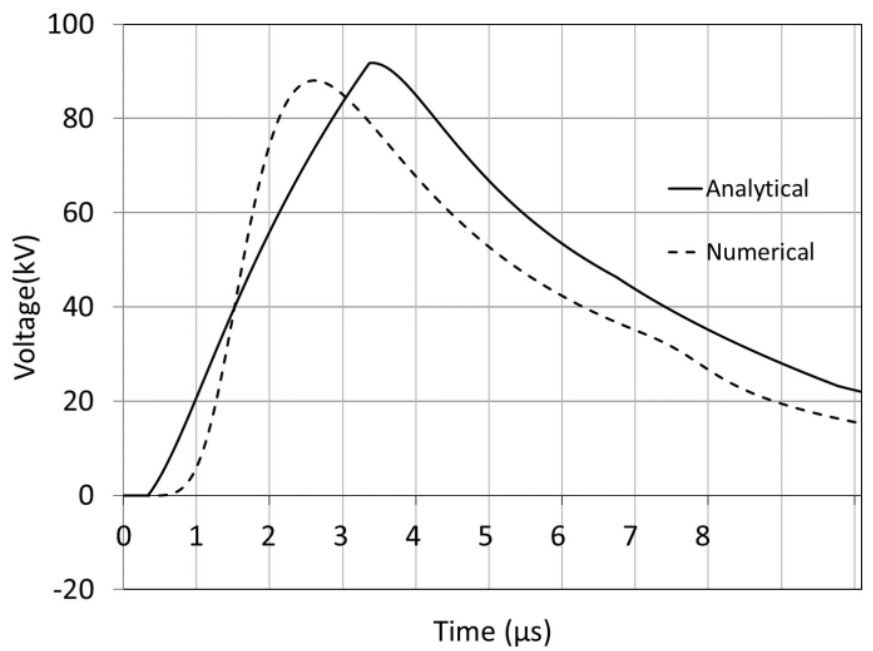

Fig. 9. Lightning-induced voltage at one extremity of the line in Fig. 4 assuming the lightning currents shown in Fig. 6. Source: Authors.

\section{CALCULATION OF FLASHOVER RATE USING THE ANALYTICAL FORMULA}

The analytical formula presented in the previous section could be employed to calculate the line flashover rate of overhead distribution lines. For this purpose, the methodology in [2] and adopted for the IEEE 1410 - 2010 standard [1] was followed. This methodology was implemented in Yaluk Draw software [12] and it consists of the following steps:

Step 1. Randomly generate a large number of lightning strike events $n_{\text {tot }}$, including parameters that allow to characterize its waveform and location, peak current $I_{p}$, front time $t_{f}$, and spatial location based on Cartesian coordinates $X_{o}$ and $Y_{0}$. Parameters $I_{p}$ and $t_{f}$ are represented by a lognormal distribution, according to CIGRÉ [15]. The front time $t_{f}$ is obtained from the peak current distribution assuming a 0.47 correlation factor. The coordinates of the strike $\left(X_{o}\right.$ and $\left.Y_{0}\right)$ are assumed to be uniformly distributed over a rectangular area with dimensions $x_{\max }$ and $y_{\max }$. Those dimensions are chosen because induced voltages associated with strokes beyond this distance are generally lower than the CFOs used in this paper.
Step 2. Lightning strikes located at a distance equal to or less than $d_{\min }$ from the line are identified as direct strikes and are not taken into account in the lightninginduced flashover analysis. The distance (15) is obtained from the electrogeometric model in [16][17][18], where $h$ is the line height, $r_{s}=10 I_{p}{ }^{0.65}$ and $r_{g}=0.9 r_{s}$.

$$
d_{\min }=\sqrt{r_{s}^{2}-\left(r_{g}-r_{h}\right)^{2}}
$$

Step 3. The remaining events are considered indirect lightning strikes and induced voltages are calculated using Yaluk Draw software [12], which included the analytical formulation for the electromagnetic field computation. The normalization of the annual number of flashovers due to indirect lightning is given by (16):

$$
F_{p}=200 \frac{n}{n_{t o t}} N_{g} y_{\max }
$$

where $n$ is the number of events that generate induced voltages that exceed 1.5. $\mathrm{CFO}$ and

$N_{g}$ is the annual ground flash density (in flashes $/ \mathrm{km} / \mathrm{yr}$ ).

$y_{\max }$ is the distance beyond added none of the events causes flashovers on overhead lines. 
This section details the application of the last methodology to the simulation of an overhead line, such as the one in Fig. 4, which matches the simulation in [2] and meets IEEE 1410-2010 standard [1]. The total number of simulated strikes $n_{\text {tot }}$ was 120,000 , and the ground flash density $N_{g}$ was $1 \mathrm{flash} / \mathrm{km}^{2}$-year. A modern computer was used: $3.4 \mathrm{GHz}$ processor and $8 \mathrm{~GB}$ RAM.

Fig. 10 and Fig. 11 compare the flashover rates obtained by applying the methodology described in this paper (called Yaluk-
MC) and the rate in IEEE 1410 , considering infinite conductivity and $\sigma=0.01 \mathrm{~S} / \mathrm{m}$, respectively. A good match between the results of the two methodologies under analysis can be observed, with errors lower than $5 \%$.

On average, a simulation takes $5.2 \mathrm{~s}$ when the numerical methodology is used. By contrast, using the analytical formulation, it takes $2.4 \mathrm{~s}$. This is a $50 \%$ reduction, which is also applicable to the calculation of the flashover rate.

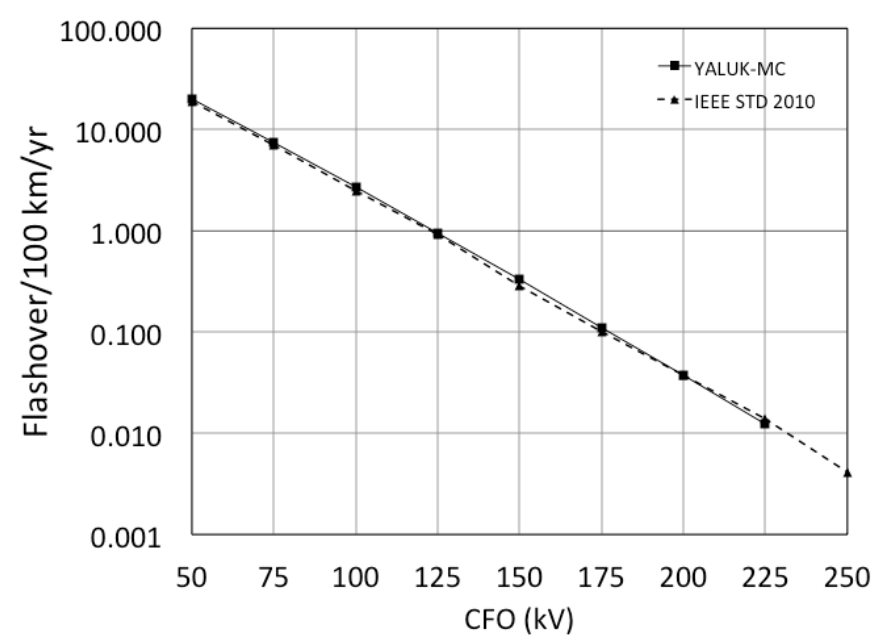

Fig. 10. Line flashover rate using the methodology in this paper (YALUK-MC) and IEEE Standard in case of a 10-m-high, 2km-long single conductor above an ideal ground. Source: Authors.

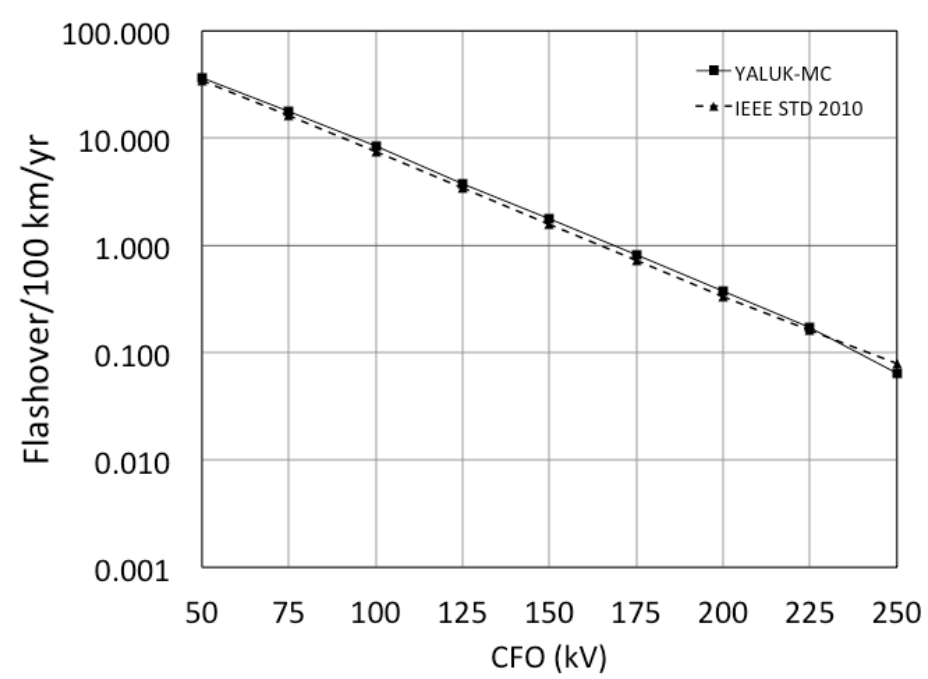

Fig. 11. Line flashover rate using the methodology in this paper (YALUK-MC) and IEEE Standard in case of a 10-m-high, 2$\mathrm{km}$-long single conductor with soil conductivity of $0.001 \mathrm{~S} / \mathrm{m}$. Source: Authors.

[60] TecnoLógicas, ISSN-p 0123-7799 / ISSN-e 2256-5337, Vol. 21, No. 42, mayo-agosto de 2018, pp. 51-62 


\section{CONCLUSIONS}

The assumption of a current wave shape linearly rising with flat top allows to derive an analytical expression for a lightning electromagnetic field over flat ground. According to the results presented in this work, such electromagnetic fields have good agreement compared with the numerical solution using a much more complex wave shape, such as Heidler function. The errors were found to be lower than $5 \%$, if the Heidler function is assumed to be the most accurate one.

Since to calculate the lightning-induced voltages it is necessary to compute the horizontal electric field above ground, the contribution of the image dipole must be derived, as shown in Section 2.

Since the results of induced voltages' peak value exhibit good agreement with the numerical simulation, the lightning performance of a distribution line can be assessed with lower computational effort and time. Thanks to the implementation presented in this paper, the analytical formulation was two times faster than using a numerical computation.

\section{REFERENCES}

[1] IEEE Power \& Energy Society, IEEE Guide for Improving the Lightning Performance of Electric Power Overhead Distribution Lines. New York, New York, USA: IEEE, 2011.

[2] A. Borghetti, C. A. Nucci, and M. Paolone, "An Improved Procedure for the Assessment of Overhead Line Indirect Lightning Performance and Its Comparison with the IEEE Std. 1410 Method," IEEE Trans. Power Deliv., vol. 22, no. 1, pp. 684-692, Jan. 2006.

[3] C. A. Nucci, F. Rachidi, M. V. Ianoz, and C. Mazzetti, "Lightning-induced voltages on overhead lines," IEEE Trans. Electromagn. Compat., vol. 35, no. 1, pp. 75-86, 1993.

[4] E. Pérez and H. Torres, "Advances On Modeling And Experimentation Of Lightning Induced Voltages On Distribution Lines," Universidad Nacional de Colombia, Bogota, 2006.

[5] M. Paolone et al., "Lightning
Electromagnetic Field Coupling to Overhead Lines: Theory, Numerical Simulations, and Experimental Validation," IEEE Trans. Electromagn. Compat., vol. 51, no. 3, pp. 532-547, Aug. 2009.

[6] R. Thottappillil, J. Schoene, and M. A. Uman, "Return stroke transmission line model for stroke speed near and equal that of light," Geophys. Res. Lett., vol. 28, no. 18, pp. 3593-3596, Sep. 2001.

[7] M. Rubinstein and M. A. Uman, "Methods for calculating the electromagnetic fields from a known source distribution: application to lightning," IEEE Trans. Electromagn. Compat., vol. 31, no. 2, pp. 183-189, May 1989.

[8] Cé. F. Barbosa and J. O. S. Paulino, "An Approximate Time-Domain Formula for the Calculation of the Horizontal Electric Field from Lightning," IEEE Trans. Electromagn. Compat., vol. 49, no. 3, pp. 593-601, Aug. 2007.

[9] F. Napolitano, "An Analytical Formulation of the Electromagnetic Field Generated by Lightning Return Strokes," IEEE Trans. Electromagn. Compat., vol. 53, no. 1, pp. 108-113, Feb. 2011.

[10] M. A. Uman, D. K. McLain, and E. P. Krider, "The electromagnetic radiation from a finite antenna," Am. J. Phys., vol. 43, no. 1, pp. 3338, Jan. 1975.

[11] M. Rubinstein and M. A. Uman, "Transient electric and magnetic fields associated with establishing a finite electrostatic dipole, revisited," IEEE Trans. Electromagn. Compat., vol. 33, no. 4, pp. 312-320, 1991.

[12] E. Pérez and E. Soto, "Yaluk Draw: Software especializado para análisis del desempeño de líneas de distribución ante impacto de rayos. Avances en Ingeniería Eléctrica," Av. en Ing. Eléctrica, vol. 4, no. 1, pp. 1-8, 2013.

[13] C. A. Nucci, A. Borghetti, M. Paolone, P. Boselli, M. Bernardi, and S. Malgarotti, "Lightning-Induced Voltages on Overhead Distribution Lines: Theoretical and Experimental Investigation of Related Problems and their Impact on Power Quality," in Cigré 2004 Session, 2004, pp. 110.

[14] S. Rusck, Induced Lightning Over-voltages on Power Transmission Lines with Special Reference to the Overvoltage Protection of Low-voltage Networks, vol. 120. Lindståhl, 1958.

[15] Rubinstein, M, Methods for Calculating Electromagnetic Fields from a Known Source Distribution: Application to Lightning. IEEE Trans. on Electromagnetic Compatibility, vol. 31 , no 2 , p. $183-189,1989$ 
Implementation of an analytical formulation for LEMP to assess the lightning performance of a distribution line

[16] Cigre Sc33 Wg01, "Guide to procedures for estimating the lightning performance of transmission lines," CIGRE Rep. 63, vol. 01, no. October, pp. 1-64, 1991.

[17] IEEE Working Group, "Calculating the lightning performance of distribution lines," IEEE Trans. Power Deliv., vol. 5, no. 3, pp.
1408-1417, 1990.

[18] Working Group on Estimation Lightning Performance of Transmission Lines, "A Simplified Method for Estimating Lightning Performance of Transmission Lines," IEEE

Power Eng. Rev., no. 4, pp. 48-48, Apr. 1985. 